\title{
Nanoformulation of antiretroviral drugs enhances their penetration across the blood brain barrier in mice'
}

\author{
Luisa Fiandra, $\mathrm{PhD}^{\mathrm{b}}$, Miriam Colombo, $\mathrm{PhD}^{\mathrm{c}}$, Serena Mazzucchelli, $\mathrm{PhD}^{\mathrm{b}}$, Marta Truffi, $\mathrm{PhD}^{\mathrm{a}}$, \\ Benedetta Santini, BPharm ${ }^{\mathrm{c}}$, Raffaele Allevi, CLT ${ }^{\mathrm{a}}$, Manuela Nebuloni, PhD ${ }^{\mathrm{a}}$, \\ Amedeo Capetti, $\mathrm{MD}^{\mathrm{b}}$, Giuliano Rizzardini, $\mathrm{MD}^{\mathrm{b}}$, Davide Prosperi, $\mathrm{PhD}^{\mathrm{c}, \mathrm{d}}$, Fabio Corsi, $\mathrm{MD}^{\mathrm{a}, *}$ \\ a Dipartimento di Scienze Biomediche e Cliniche "Luigi Sacco", Università di Milano, Milano, Italy \\ ${ }^{\mathrm{b}}$ Ospedale L. Sacco, Milano, Italy \\ ${ }^{\mathrm{c}}$ Dipartimento di Biotecnologie e Bioscienze, Università di Milano-Bicocca, Milano, Italy \\ ${ }^{\mathrm{d}}$ Laboratorio di Biofisica e Nanomedicina, Polo Tecnologico, Fondazione Don Gnocchi IRCCS-ONLUS, Milan, Italy \\ Received 24 June 2014; accepted 19 March 2015
}

\begin{abstract}
Eradication of virus by sanctuary sites is a main goal in HIV management. The central nervous system (CNS) is a classic model of sanctuary where viral replication occurs despite a complete viral suppression in peripheral blood. In recent years, nanotechnologies have provided a great promise in the eradication of HIV from the CNS. We hereby demonstrate for the first time that the structurally complex antiretroviral drug enfuvirtide (Enf), which normally is unable to penetrate the cerebrospinal fluid, is allowed to cross the blood brain barrier $(\mathrm{BBB})$ in mice by conjugation with a nanoconstruct. Iron oxide nanoparticles coated with an amphiphilic polymer increase Enf translocation across the BBB in both in vitro and in vivo models. The mechanism involves the uptake of nanoconjugated-Enf in the endothelial cells, the nanocomplex dissociation and the release of the peptide, which is eventually excreted by the cells in the brain parenchyma.
\end{abstract}

(C) 2015 Published by Elsevier Inc.

Key words: HIV sanctuaries; Enfuvirtide; Blood brain barrier; PMA-coated nanoparticles

\section{Background}

Current antiretroviral treatment regimens suppress plasma HIV-1 RNA and DNA below detectable levels in a consistent proportion of subjects. ${ }^{1}$ However, functional cure and eradication are still beyond our possibilities. One obstacle to such goals is represented by the difficulty to achieve therapeutic antiretroviral concentrations within sanctuary sites where HIV-1 has been shown to compartmentalize. Such sites include the genital tract, 29 the gut-associated lymphoid tissue, the lymph nodes, tissue 30 macrophages and the central nervous system (CNS). ${ }^{2-4}$ In 31 particular, the CNS is considered one of the most important viral 32 reservoirs. This is mainly due to the presence of macrophages 33 that promote the inflammatory escalation with subsequent 34 astrogliosis and neurodegeneration, thus establishing the 35 so-called NeuroAIDS, ${ }^{5}$ responsible for neurocognitive disorders 36

Abbreviations: AF660, Alexa Fluor 660; BBB, blood brain barrier; CNS, central nervous system; DLS, dynamic light scattering; ECM, endothelial cell medium; Enf, enfuvirtide; Epf, epifluorescence; FI, fluorescence intensity; FD40, FITC-Dextran 40; FITC, fluoresceinamine; HAART, highly active anti-retroviral therapy; ICP-OES, inductively coupled plasma optical emission spectrometry; MRP, multidrug resistance-associated protein; $P_{\text {app }}$, apparent permeability coefficient; PBS, phosphate buffer saline; PFA, paraformaldehyde; PMA, poly(isobutylene-alt-1-tetradecene-maleic anhydride); RBMVECs, rat brain microvascular endothelial cells; RT, room temperature; SE, standard errors; SEM, scanning electron microscopy; TEM, transmission electron microscopy; TEER, transendothelial electrical resistance.

This work was supported by the Fondazione Regionale per la Ricerca Biomedica (FRRB), NanoMeDia Project (Regione Lombardia and "L. Sacco" Hospital), and by the "Fondazione Romeo ed Enrica Invernizzi".

M.T. acknowledges "Centro di Microscopia Elettronica per lo sviluppo delle Nanotecnologie applicate alla medicina" (CMENA, University of Milan) for the postdoctoral fellowship.

*Corresponding author at: Dipartimento di Scienze Biomediche e Cliniche "Luigi Sacco", Università di Milano, Milano, Italy.

E-mail address: fabio.corsi@unimi.it (F. Corsi). 
with different grades of severity (AIDS dementia complex). From a clinical point of view, NeuroAIDS is a real challenge since the blood brain barrier is poorly crossable by most antiretroviral drugs. ${ }^{2}$

In the effort toward viral eradication, one of the most promising strategies is to treat this latent-T cell reservoir, so that resting cells may be induced to release virions and reactivate, ${ }^{6-9}$ while preventing HIV-1 entry in uninfected CD4 + T cells. With this aim it would be important to design new therapeutic strategies to direct antiretroviral drugs in these HIV sanctuaries, both to reduce T-cell mediated delivery of the virus into the sanctuaries and to directly act on HIV-sensitive CD4+ cells inside these sites (i.e. microglial cells of brain) ${ }^{4}$.

Nanotechnology is an emerging multidisciplinary field that has the potential to offer a radical change in the treatment and monitoring of HIV/AIDS. ${ }^{10-13}$ The potential advantages in using nanoparticles for HIV infection treatment include the capacity to incorporate, encapsulate, or conjugate a variety of drugs in order to target specific cell populations, grant long-term drug release, and penetrate into sanctuary sites. With regard to the CNS, the employment of nanotechnology could allow antiretroviral drugs to effectively reach this reservoir, ${ }^{14}$ thus preventing the replication of the virus and reducing the damages induced by the infection.

In current clinical practice, the first-line antiretroviral therapy is generally constituted by a combination of two nucleoside reverse transcriptase inhibitors (NRTI) with a non-nucleoside reverse transcriptase inhibitor (NNRTI), such as a protease inhibitor or an integrase inhibitor. Conversely, fusion inhibitors are much less used because of some well-known limitations such as production time and costs, difficult administration (subcutaneous injection twice daily) and adverse effect profile. ${ }^{15}$ Therefore, fusion inhibitors are only used in case of resistance or failure of the HAART. Enfuvirtide (Fuzeon ${ }^{\mathrm{TM}}$ from Roche Laboratories Inc. and Trimeris Inc.) is a 36-amino acid peptide that targets multiple sites in gp41, a HIV glycoprotein responsible for the fusion with CD4+ cells. $^{16-18}$ Enfuvirtide (Enf) inhibits HIV-1-mediated cell-cell fusion and transmission of cell-free virus while it does not have substantial activity against HIV-2. ${ }^{19-22}$ Because of its unfavorable pharmacological profile, with a half life of approximately $2 \mathrm{~h}$ and a high molecular weight ( $4.5 \mathrm{kDa})$, Enf is particularly indicated to provide a proof of concept of the improved access of antiretroviral drug to HIV sanctuaries by nanoformulation. Indeed, Enf does not penetrate the $\mathrm{BBB}$ because of its complex structure, and is therefore not detectable in cerebrospinal fluid (CSF). ${ }^{23}$

Aim of our study is to demonstrate the ability of iron oxide nanoparticles coated with PMA amphiphilic polymer (MYTS) to enhance the permeation of a high-weighted molecule, such as Enf, across the BBB both in in vitro and in vivo models, and propose a mechanism for drug delivery across the endothelium.

\section{Methods}

Nanoparticle design

Magnetic nanoparticles (MNP) were synthesized by solvothermal decomposition in organic solvent from organometallic precursors according to Park et al. protocol. ${ }^{24} \mathrm{MNP}$ were transferred to water phase using a fluorescent labeled amphi- philic polymer (PMA). ${ }^{25}$ Fluorescent-PMA was obtained with 92 fluoresceinamine $1.0 \mathrm{M}(0.5 \mathrm{~mL}$ in DMSO $)$ was added to a 93 $0.5 \mathrm{M}$ PMA in $\mathrm{CHCl} 3(5 \mathrm{~mL})$ and the mixture was left overnight 94 at RT. Part of this solution $(20 \mu \mathrm{L})$ was added to MNP $(1.5 \mathrm{mg} 95$ in $\mathrm{CHCl} 3)$. The organic solvent was evaporated and sodium 96 borate buffer (SBB, pH 12, $20 \mathrm{~mL}$ ) was added obtaining a stable 97 nanoparticle dispersion which was concentrated in Amicon tubes 98 (100 kDa filter cutoff) by centrifuging at $3500 \mathrm{rpm}$ for $20 \mathrm{~min}$. 99 The nanoparticles were washed twice with water resulting in 100 green labeled PMA-coated nanoparticles highly soluble in 101 aqueous media (MYTS). MYTS were reacted with an amino- 102 linker useful for Enf immobilization on the nanoparticles. Enf 103 was previously labeled with AF660 dye (Invitrogen, Carlsbad, 104 CA) according to manufacturer's protocol. The final double 105 labeled Enf-MYTS are schematically represented in Figure 1, A. 106

\section{Characterization of the $B B B$ in vitro model}

107

The setting of the BBB in vitro model, based on a co-colture of 108 RBMVECs and astrocytes, is described in Supplementary 109 materials. Before each experiment, we checked the trans-BBB 110 electrical resistance by an EVOM $^{2}$ Epithelial tissue Volt/Ohmmeter 111 connected to an Endohm-24SNAP cup (WPI, Germany), obtaining 112 a suitable value on $90 \%$ of the inserts. Moreover, the trans-BBB 113 apparent permeability coefficient of FITC-Dextran 40 (FD40) 114 was determined by measuring the flux of the molecule from the 115 upper to the lower chamber of three BBB systems at $1 \mathrm{~h}, 2 \mathrm{~h}$ and 116 $3 \mathrm{~h}$ from the addition of $1 \mathrm{mg} \mathrm{mL}^{-1}$ FD40 in the upper 117 compartment. The flux through the RBMVECs single layer or 118 through the empty insert was used as control. The amount of 119 FD40 recovered in the lower compartment was determined 120 spectrofluorimetrically and the $P_{\text {app }}$ was calculated from the 121 mean flux (see Supplementary materials).

122

In vitro trans- $B B B$ permeation

123

The permeation of (AF660)Enf, (FITC)MYTS or 124 (AF660)Enf-MYTS(FITC) across the BBB was assessed on 125 the in vitro model described above, using four inserts for each 126 experimental condition. The two formulations were added to the 127 upper chamber and, after 4 or $7 \mathrm{~h}$ of incubation, a defined 128 volume of ECM was collected by both the upper and the lower 129 chambers. The fluorescence intensity of the samples was 130 measured spectrophotometrically. For an exact comparison 131 between the trans-BBB permeation of free and MYTS-conju- 132 gated $\operatorname{Enf}\left(5 \mu \mathrm{g} \mathrm{mL}^{-1}\right)$, the FI of the two formulations was used 133 for normalization, and the final amount of Enf-MYTS in the 134 upper chamber was $0.1 \mathrm{mg} \mathrm{mL}^{-1}$.

ICP-OES was also used to quantify the amount of MYTS iron 136 in the collected samples.

Reported results are representative of one of three indepen- 138 dent experiments.

Plasma concentration measurements in mice

Plasma concentration of free or conjugated Enf was 141 determined upon intravenous injection AF660-labeled Enf 142 $\left(0.2 \mu \mathrm{g} \mathrm{g}^{-1}\right.$ body weight) or Enf-MYTS $\left(12.5 \mu \mathrm{g} \mathrm{g}^{-1}\right.$ body 143 weight) in Balb/c mice. We treated four mice per experimental 144 condition and repeated the experiment twice (for a total of eight 145 

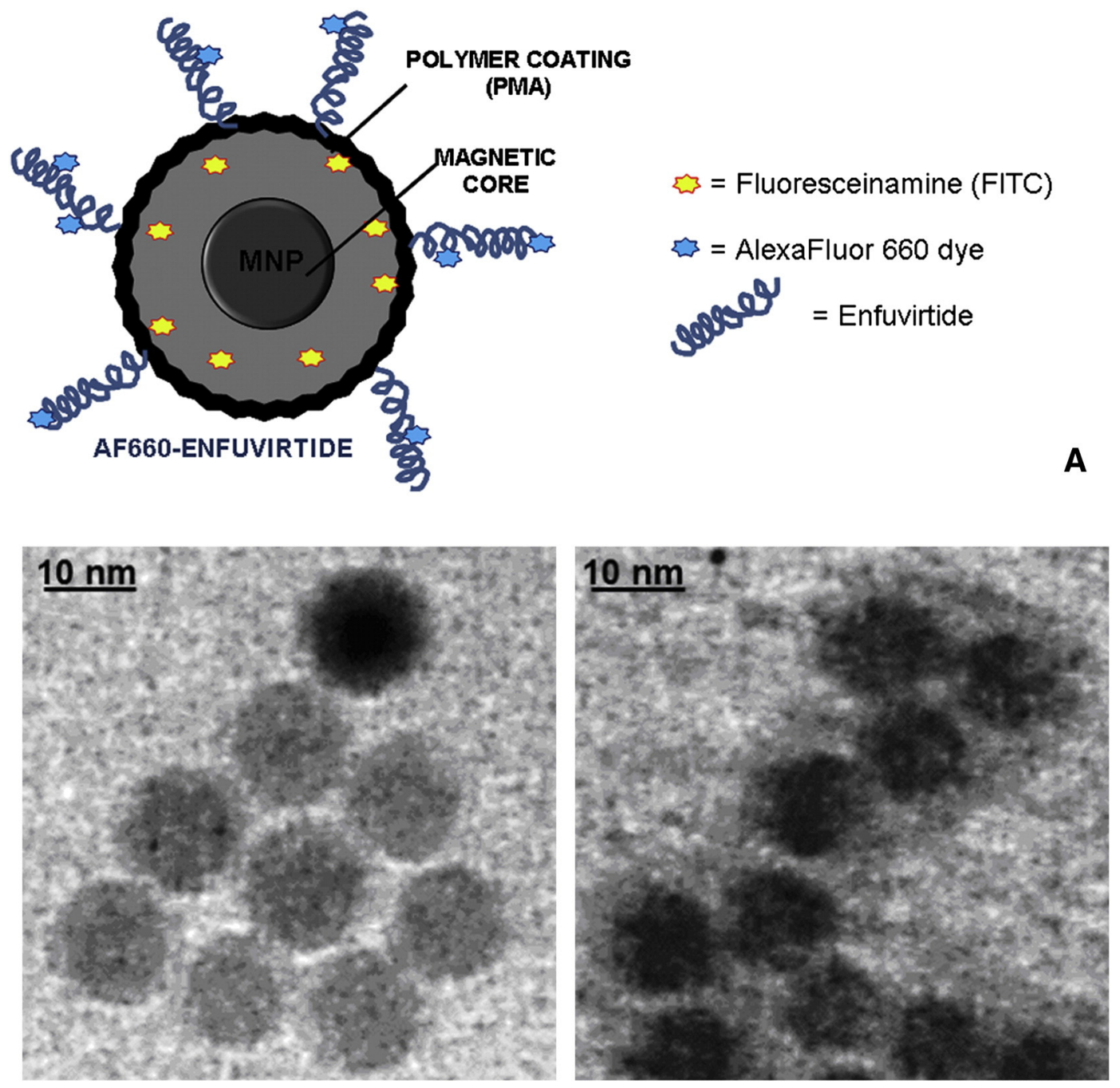

B

Figure 1. (A) Schematic representation of labeled Enf-MYTS. (B) TEM images of MNP in hexane (left) and MYTS in water (right).

animals per experimental condition). The amount of injected Enf-MYTS was calculated normalizing the fluorescence intensity of conjugated Enf to that of the free peptide. After $30 \mathrm{~min}$, $1 \mathrm{~h}$ and $6 \mathrm{~h}$ postinjection, blood was collected and its fluorescence intensity was determined spectrofluorimetrically. After subtraction of background fluorescence, determined in samples collected from mice before treatment, the amount of Enf was calculated by using a calibration curve with known amounts of the compounds dissolved in control plasma samples.

\section{Ex vivo IVIS imaging}

Mice injected with (AF660)Enf or (AF660)Enf-MYTS (three animals for each experimental group were employed in three different experiments, for a total of nine mice) were sacrificed $1 \mathrm{~h}$ after injection and dissected brains were analyzed in an IVIS Lumina II imaging system (Calipers Life Sciences, UK), together with the brains from three non-treated mice. Images were acquired with a Cy5 emission filter, while excitation was scanned from 570 to $640 \mathrm{~nm}$ and tissue autofluorescence was 163 removed by spectral unmixing.

Confocal laser scanning microscopy

For the confocal observations of brain cryosections, portions 166 of the same tissues analyzed by IVIS or of additional tissues 167 isolated from mice injected with $0.2 \mu \mathrm{g} \mathrm{g}^{-1}$ body weight 168 (AF660)Enf, or $12.5 \mu \mathrm{g} \mathrm{g}^{-1}$ body weight (FITC)MYTS, 169 (AF660)Enf-MYTS or (AF660)Enf-MYTS(FITC) (three ani- 170 mals for each experimental group), were fixed, freezed in liquid 171 nitrogen and cryosectioned. Cryosections were counterstained 172 with DAPI and NeuroTrace 530/615 fluorescent Nissl stain or 173 immunodecorated with anti-CD31.

For the confocal microscopy of RBMVECs (three inserts for 175 each experimental condition), cells on insert were fixed and 176 immunodecorated with anti-CD31 and DAPI.

Images were acquired by a Leica TCS SPE confocal 178 microscope and the intracellular distribution of AF660 and 179 FITC signals was analyzed by ImageJ software. 
Each image is representative of at least six images obtained from three inserts or mice brain sections for each experimental condition.

\section{Scanning and transmission electron microscopy}

For TEM analysis, MYTS were dispersed under sonication in water $\left(50 \mu \mathrm{g} \mathrm{mL}^{-1}\right)$ and a drop of the resulting solution was placed on a formvar/carbon-coated copper grid and air-dried.

RBMVECs layered on inserts and exposed or not to $0.1 \mathrm{mg}$ Enf-MYTS or MYTS, and sections of mice brains, exposed in vivo to the same nanoformulates $\left(12.5 \mu \mathrm{g} \mathrm{g}^{-1}\right.$ body weight), were analyzed by TEM, by fixing small portions of cells-bearing inserts $(n=3)$ or tissues (pieces obtained from the same brains employed for confocal microscopy analyses) in $2.5 \%$ glutaraldehyde. For scansion electron microscopy analyses, other small portions of the RBMVECs-bearing inserts were fixed and processed as described in Supplementary materials.

\section{Histopathology}

Brain, liver, kidneys, spleen and lung samples obtained from three Balb/c mice, whose brains were analyzed by confocal microscopy, were fixed in $10 \%$ buffered formalin for at least $48 \mathrm{~h}$ and embedded in paraffin. Three $\mu \mathrm{m}$ sections were cut, stained with hematoxylin and eosin and examined blindly.

\section{Statistical analysis}

All mean values $\pm \mathrm{SE}$ reported in Results section and in Supplementary materials were compared by Student's $t$ test.

\section{Results}

\section{Nanoparticle characterization}

MNP and the final Enf-MYTS, synthesized as described in Methods and Supplementary materials, were characterized in size and shape by DLS and TEM (Figure 1, B). MNP had a hydrodynamic diameter of $18.8 \mathrm{~nm} \pm 2.1$ in hexane. After the phase transfer, MNP maintained the original average crystal size ( $8 \mathrm{~nm}$ by TEM), and the final nanoparticle shape was uniformly spherical, with a hydrodynamic diameter of $23.9 \pm 2.0 \mathrm{~nm}$ (MYTS in water) as determined by DLS. After drug conjugation, the nanoparticle size increased up to $35.2 \pm 2.2 \mathrm{~nm}$. The $\mathrm{pH}$ value of the suspension was around 5.5 and the zeta potential obtained at this $\mathrm{pH}$ value was $-29.58 \pm 1.90 \mathrm{mV}$, likely suggesting a high stability of Enf-MYTS with minimal aggregation in water medium at this $\mathrm{pH}$. Indeed a zeta potential value higher than $\pm 30 \mathrm{mV}$ is generally required for a colloidally stable nanoparticle dispersion. ${ }^{26,27}$

\section{Nanoconjugated enfuvirtide crosses the in vitro BBB model}

The efficiency of MYTS in increasing the trans-BBB permeation of Enf was first evaluated on an in vitro $\mathrm{BBB}$ model consisting of a double layer of astrocytes and RBMVECs. Before treatment, the integrity of our experimental model was validated by measuring TEER and by determining the trans-BBB apparent permeability of the Dextran 40. In all BBB models devoted to the subsequent experimental phase, we recorded a mean TEER value higher than $400 \Omega \mathrm{cm}^{2}$. BBB selectivity to the
Dextran 40 labeled with FITC (FD40) was assessed in some 231 additional inserts by measuring the trans-BBB flux over $3 \mathrm{~h} 232$ (Figure S1). The resulting $P_{\text {app }}\left(0.10 \pm 0.03 \times 10^{-7} \mathrm{~cm} \mathrm{~s}^{-1}, 233\right.$ mean $\pm \mathrm{SE}, \mathrm{n}=6$ ) confirmed the production of a very tight 234 barrier. SEM observations showed the presence of a uniform 235 layer of endothelial cells (Figure S2A), and TEM images clearly 236 demonstrated that cells were connected by well-structured tight 237 junctions (Figure S2B).

The permeability of Enf, MYTS and Enf-MYTS across the 239 BBB model was determined by labeling the peptide and the 240 nanoparticle with AF660 and FITC, respectively (Figure 1, A). 241 The nanoparticle suspensions were added in the upper chamber 242 of the experimental apparatus and their passage through the BBB 243 model was assessed after 4 and $7 \mathrm{~h}$ of incubation by measuring 244 their fluorescence intensity (FI) into the lower chamber. We 245 found that only a small fraction of free Enf was able to cross the 246 $\mathrm{BBB}$ in vitro: after $4 \mathrm{~h}$, Enf FI in the lower chamber was about 247 $0,15 \%$ of Enf FI added in the upper chamber, and the percentage 248 increase of FI in the lower chamber over the subsequent $3 \mathrm{~h}$ of 249 incubation was 30\% (Figure 2, A). Conjugation of Enf to the 250 nanoparticle did not significantly affect its FI in the lower 251 chamber within the first four hours, but it was able to greatly 252 increase its permeation across the BBB (by over 170\%) between 253 4 and $7 \mathrm{~h}$ of incubation (Figure 2, A). Surprisingly, the 254 percentage increase of the FITC FI in the lower chamber 255 calculated between 4 and $7 \mathrm{~h}$, which is associated to MYTS 256 permeation across the BBB, was only $10 \%$, and therefore much 257 lower than that of the conjugated peptide in the same time span 258 (Figure 2, B). The great difference between the \% increase in 259 lower chamber of AF660 (conjugated to Enf) and FITC 260 (conjugated to MYTS) after incubation with the Enf-MYTS 261 nanocomplex strongly suggested that the two components did 262 not have the same fate when crossing the BBB, and that they 263 likely dissociated into the barrier to be processed separately. The 264 permeation of MYTS through the BBB was also assessed by 265 measuring the iron content in the solution collected by the lower 266 chamber by ICP-OES: we found that the percentage increase of 267 iron recorded between 4 and $7 \mathrm{~h}$ was only $1.84 \pm 0.04$ (mean \pm 268 $\mathrm{SE}, \mathrm{n}=8$ ) for both MYTS and Enf-MYTS.

Then, we measured the FI of the three formulations in the 270 lower chamber of the BBB apparatus after $24 \mathrm{~h}$ of incubation. 271 We observed that the Enf trans-BBB permeation was enhanced 272 between 7 and $24 \mathrm{~h}$ of incubation by $175 \%$ (Figure 2, $A$ ), likely 273 because of increased leakage of the RBMVEC barrier over the 274 time. However, the effect of the nanocomplexation on the 275 permeation of Enf across the BBB was still remarkable: the 276 percentage increase of AF660 FI in the lower chamber between 7277 and $24 \mathrm{~h}$ of exposure to Enf-MYTS reached 745\% (Figure 2, A). 278 By contrast, the percentage increase of FITC FI in the lower 279 chamber was about $20 \%$ for both MYTS and Enf-MYTS 280 (Figure 2, B), thus underlining a discrepancy between the FI 281 recorded for Enf and MYTS after incubation of the BBB with 282 Enf-MYTS. The percentage increase of iron content in the lower 283 chamber between 7 and $24 \mathrm{~h}$ was still negligible and comparable 284 for both conjugated and unconjugated nanoparticles $(1.89 \% \pm 285$ 0.03, mean $\pm \mathrm{SE}, \mathrm{n}=8$ ).

286

In parallel, we performed a confocal microscopy analysis of 287 the upper side of the insert after $7 \mathrm{~h}$ of incubation with Enf or 288 

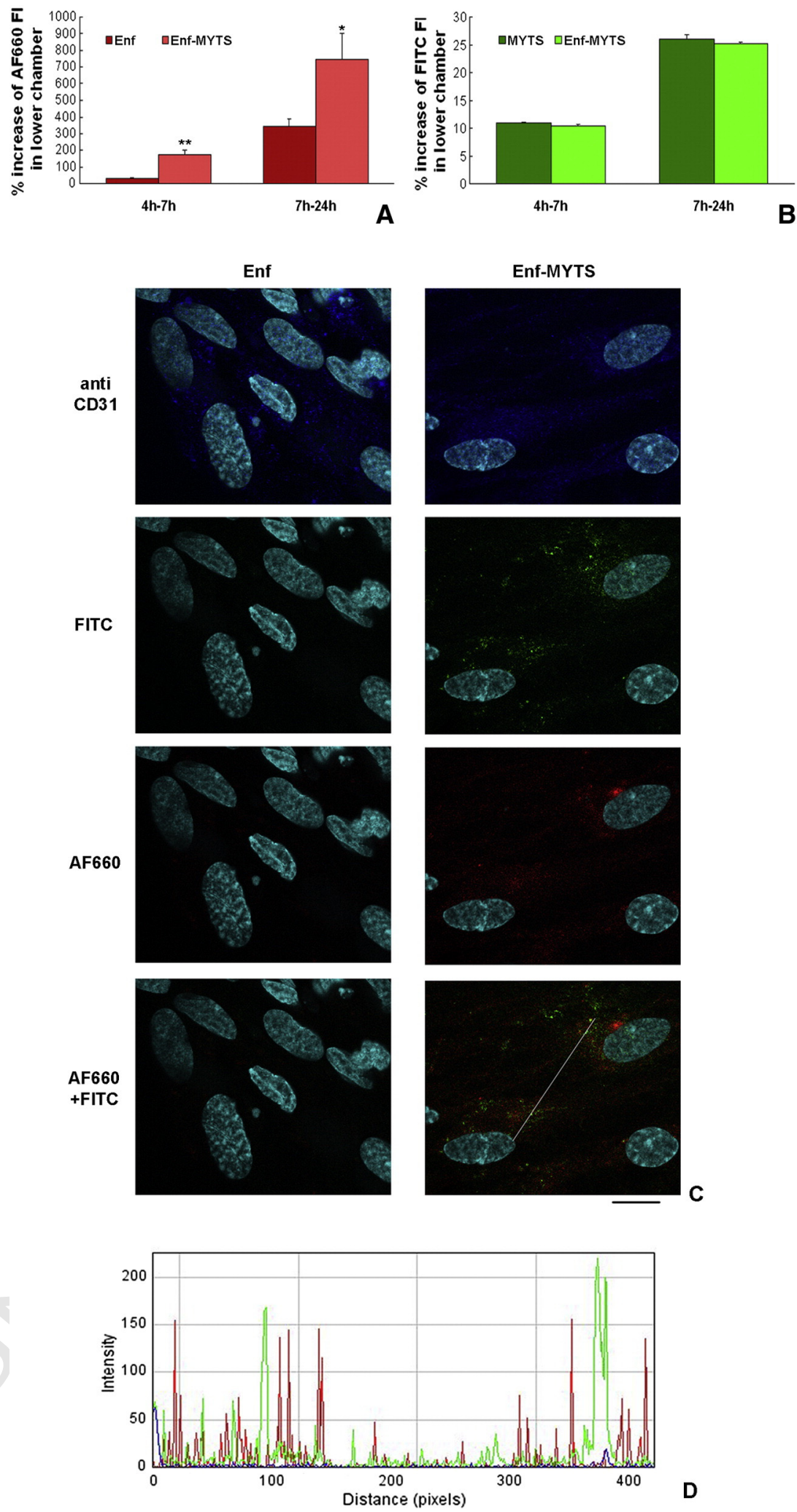

Figure 2. Percentage (\%) increase of FI of free or conjugated (AF660)Enf (A) or (FITC)MYTS (B) in the lower chamber of the BBB in vitro system calculated between 4 and $7 \mathrm{~h}$, and 7 and $24 \mathrm{~h}$, from the addition of labeled Enf, MYTS and Enf-MYTS into the upper chamber. Mean \pm SE of 4 replicates; $* * P<0,001$ and $* P<0,05$, Enf-MYTS vs Enf (Student's $t$ test) (C) Confocal laser-scanning micrographs (single optical sections) of RBMVECs after $7 \mathrm{~h}$ of incubation with free Enf or Enf-MYTS. Enf and MYTS are labeled with AF660 (red) and FITC (green) respectively; nuclei are stained with DAPI (cyan) and endothelial cells are immunodecorated with anti-CD31 antibody (blue); scale bar: $10 \mu \mathrm{m}$. (D) Overlay of the signal intensity plots of Enf and MYTS along a one-pixel line covering a cytoplasmic portion of the cells. 

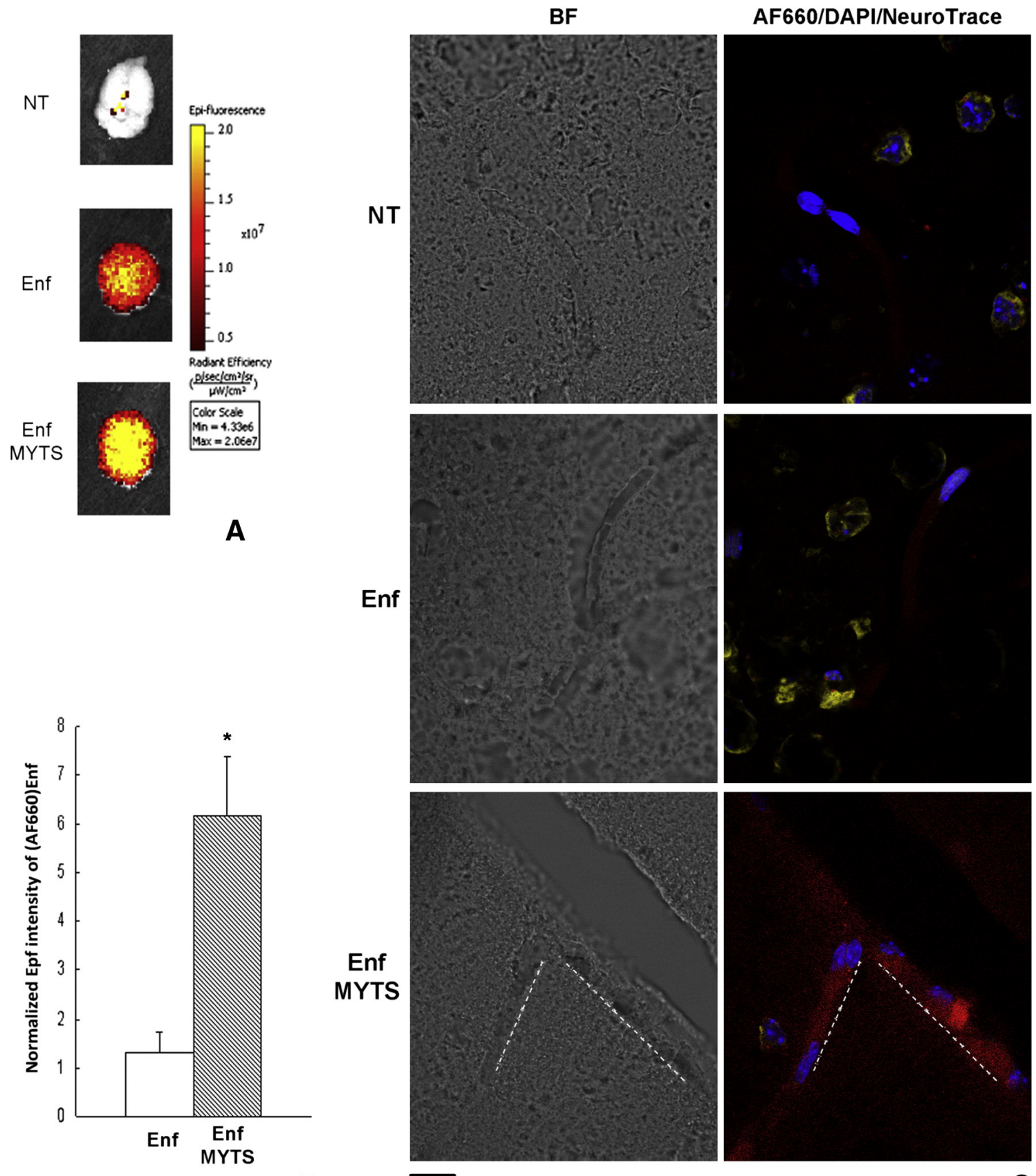

B
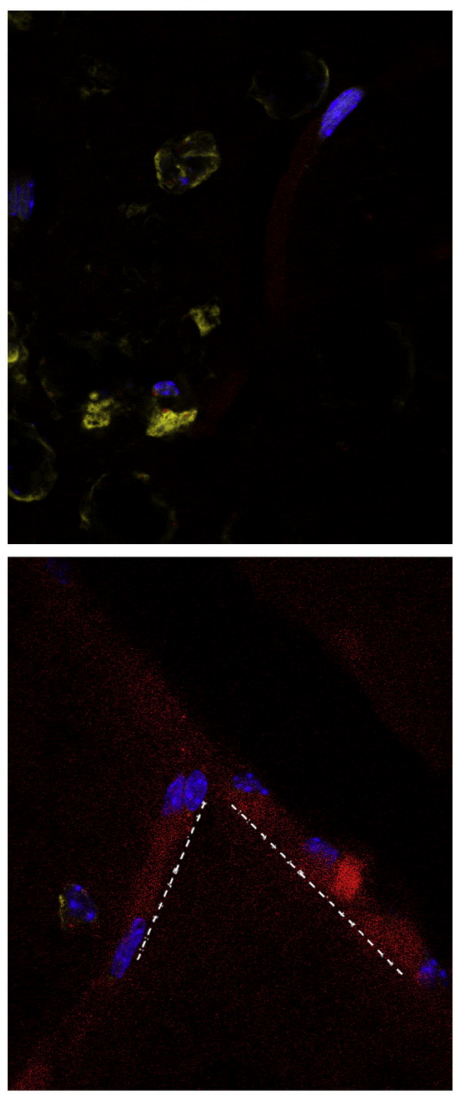

C

Figure 3. Analysis of brains isolated from non-treated mice (NT) or mice exposed for $1 \mathrm{~h}$ to free or conjugated AF660-labeled enfuvirtide. (A) Epf images of isolated brains, where Epf intensity is expressed as radiant efficiency. (B) Averaged Epf intensity of isolated brains where Epf values have been normalized on fluorescence intensity of injected solution in order to keep into account the differences in intrinsic fluorescence emission for each preparation; mean \pm SE of 9 different brains for each experimental condition; ${ }^{*} P<0,01$ (Student's $t$ test). (C) Confocal laser-scanning micrographs (single optical sections) of brain cryosections; images from control animals (NT) or from animals treated with free or nanocomplexed enfuvirtide (red) have been overlaid on the corresponding images reporting nuclei (blue) and neuronal cytoplasm (yellow), counterstained with DAPI and NeuroTrace 530/615, respectively (right column); brightfield (BF) images are reported on the left; dashed lines highlight the vessel boundaries; bar: $10 \mu \mathrm{m}$.

Enf-MYTS. Figure 2, $C$ shows that while free Enf was not internalized by the RBMVECs, the conjugation of the peptide to the nanoparticles allowed it to deeply enter into the cells, confirming the enhanced permeability of Enf when nanoconjugated. The merge image of the cells incubated with Enf-MYTS revealed that the AF660 and the FITC fluorescence were mostly non-overlapping (Figure 2, $C$ and D). These 295 image data, combined with the great difference in the 296 trans-BBB permeation rate observed between the two 297 components, strongly suggested that a dissociation of the 298 peptide from the nanoparticle might have occurred in the 299 endothelial layer. 
BF
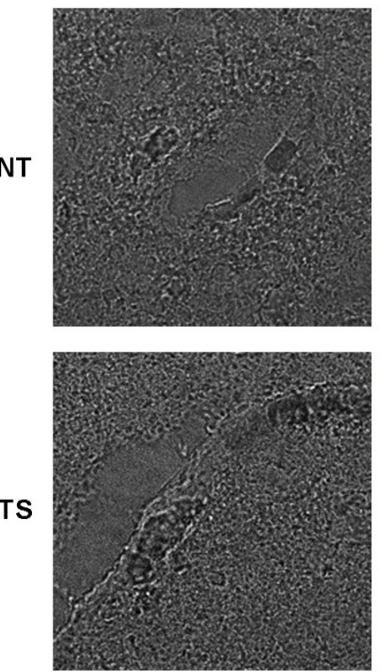

(FITC)MYTS

(AF660)Enf
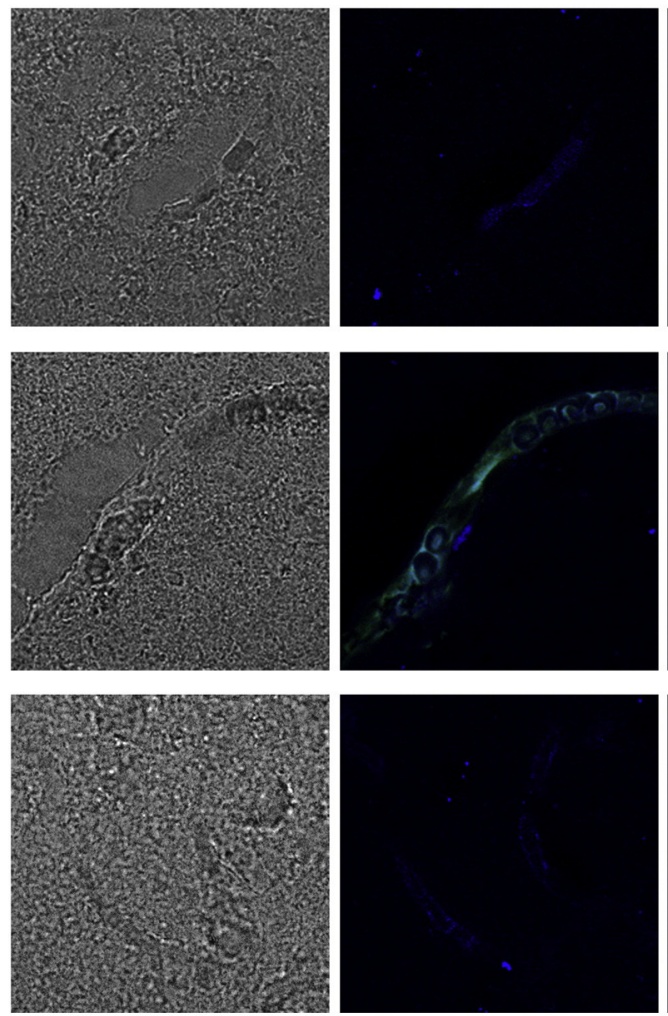

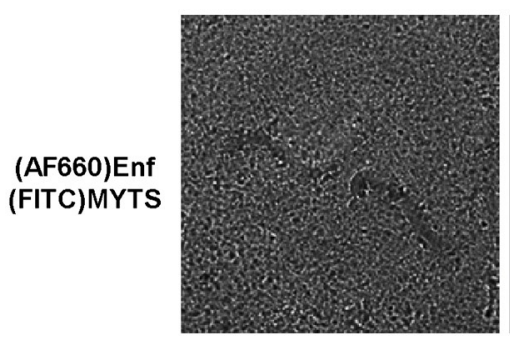

(AF660)Enf (FITC)MYTS

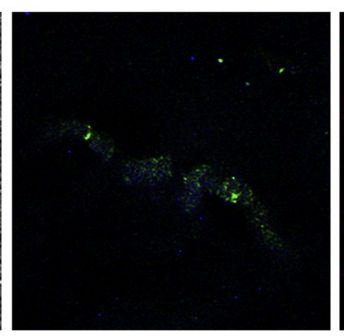

CD31/AF660
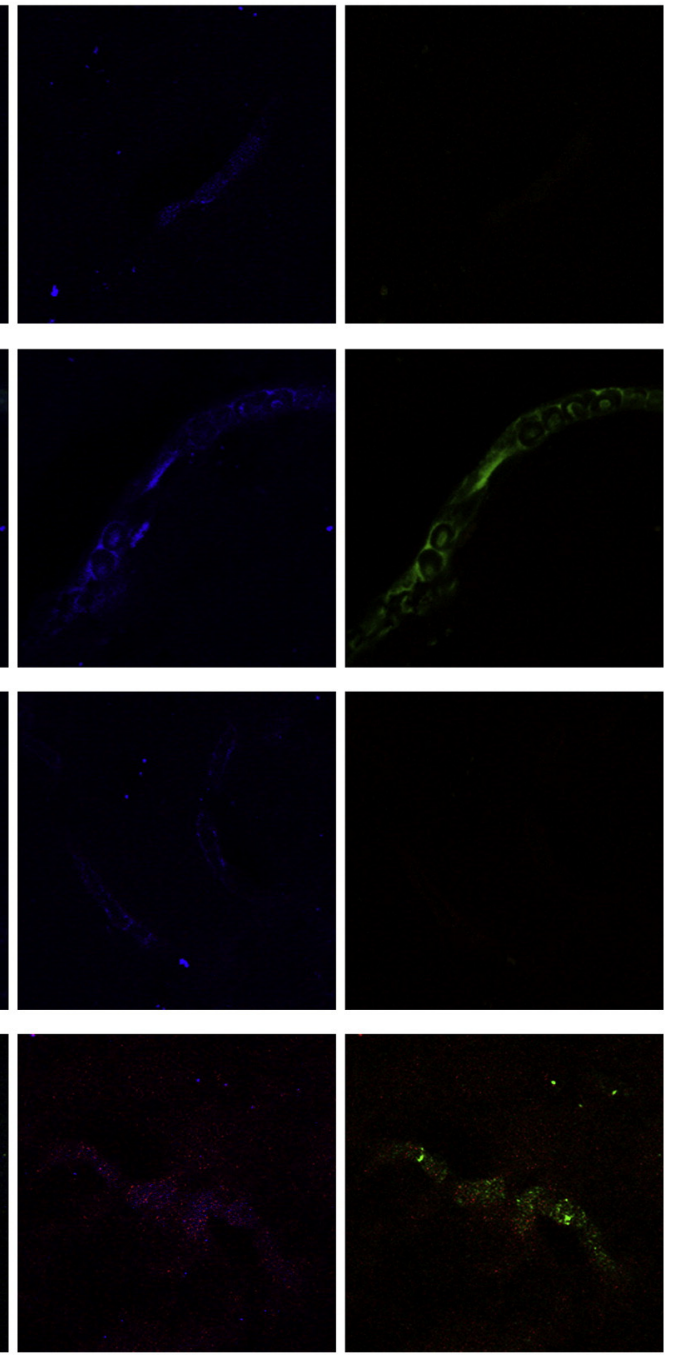

AF660/FITC
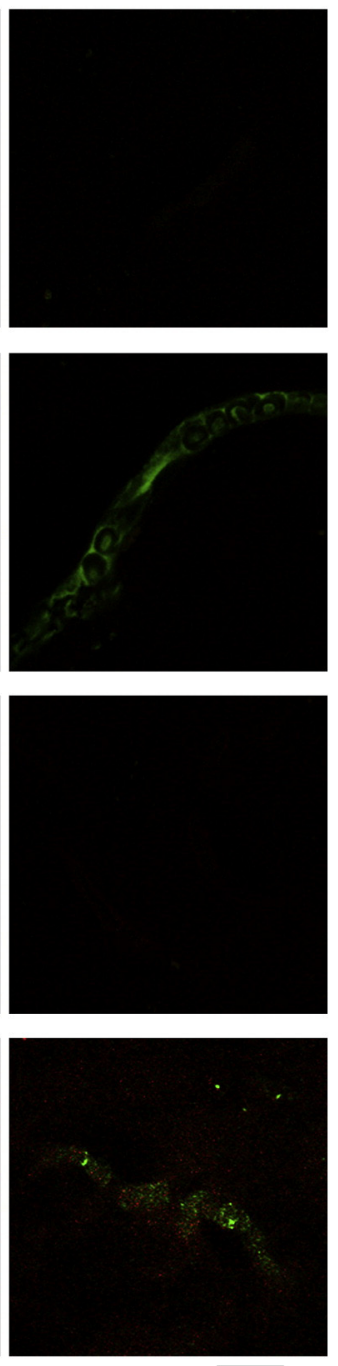

Figure 4. Confocal laser-scanning micrographs (single optical sections) of brain cryosections from non-treated mice (NT) or mice exposed for $1 \mathrm{~h}$ to (AF660)Enf, (FITC)MYTS or (AF660)Enf-MYTS(FITC); conjugated or free AF660-Enf (green) and FITC-MYTS (red) have been overlaid each other and with CD-31 stained endothelial cells (blue); brightfield (BF) images are reported on the left; bar: $10 \mu \mathrm{m}$.

\section{In vivo brain targeting and trans-BBB delivery of nanoconju-} gated enfuvirtide

Trans-BBB permeation of MYTS-conjugated Enf was then assessed in vivo in Balb/c mice intravenously injected with free Enf or with the same peptide conjugated to nanoparticles. We decided to follow the bioavailability and biodistribution of Enf, by labeling the peptide with AF660 whose efficiency as in vivo probe had been previously reported in mice. ${ }^{28,29}$ Firstly, plasma concentration of free or conjugated Enf was monitored at $30 \mathrm{~min}, 1 \mathrm{~h}$ and $6 \mathrm{~h}$ after injection in eight different animals for each experimental condition, to verify the effect of nanoconstruct on peptide bioavailability. We observed a maximal concentration of both free or conjugated drug in the blood stream within $1 \mathrm{~h}$ postinjection and a strong decrease over the following hours, up to negligible levels at $6 \mathrm{~h}$ postinjection. Moreover, Enf concentration in plasma appeared reduced by conjugation to MYTS and therefore less available for the potentially infected organs, including brains 317 (Figure S3). Other mice were injected with Enf or Enf-MYTS (nine 318 for each experimental condition) to be sacrificed at $1 \mathrm{~h} 319$ postinjection, together with three untreated animals (controls). 320 Fluorescence imaging of dissected brains revealed a significant 321 accumulation of both free and nanoformulated Enf in this organ at 322 $1 \mathrm{~h}$ postinjection, as pointed out by the strong Epf signal not 323 observed in the brain of non-treated mice (Figure 3, $A$ ), feasibly 324 due to the peptide content in the blood circulation of brain. 325 Neverthless, Epf intensity associated with nanoformulated Enf was 326 stronger than that of free Enf (Figure 3, A, B), thus suggesting a 327 higher accumulation of the nanoformulated peptide in this organ 328 despite its lower bioavailability. To determine if the observed 329 increased concentration of Enf in the brain was really associated to 330 an increased permeation of the drug across BBB by effect of the 331 nanocomplexation, we analyzed the interaction of Enf and 332 Enf-MYTS with BBB cells and of their localization in the 333 
L. Fiandra et al / Nanomedicine: Nanotechnology, Biology, and Medicine $x x$ (2015) $x x x-x x x$

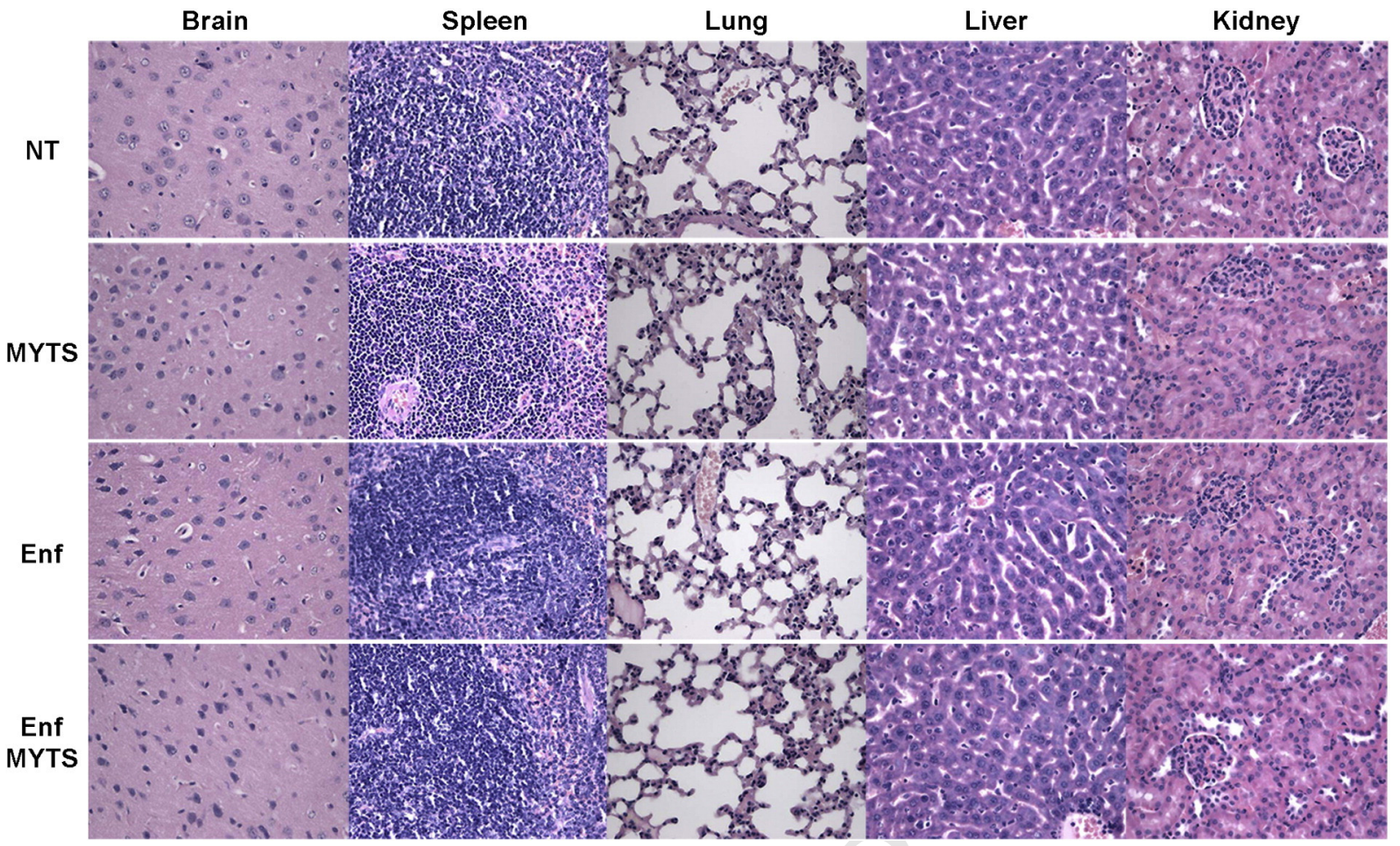

Figure 5. Histopathological analysis of brain, spleen, lung, liver and kidney dissected from non-treated (NT) mice, or from mice injected with MYTS, Enf and Enf-MYTS. Hematoxylin-eosin, $\mathrm{OM} \times 40$.

perivascular space. Cryosections of mice brains excised $1 \mathrm{~h}$ postinjection of Enf or Enf-MYTS were analyzed by confocal microscopy. Figure 3, $C$ shows enhanced fluorescence intensity in brain capillaries in samples treated with the nanoconjugated Enf when compared to the free peptide, where instead fluorescence was only slightly higher than control autofluorescence. In addition, nanocomplexation of Enf induced a spreading of fluorescence outside the boundaries of the vessel.

To confirm the efficacy of MYTS in driving Enf into the endothelial cells of brain capillaries and finally exerting an efficient trans-BBB permeation of the drug, we injected mice with MYTS, Enf or Enf-MYTS (three mice for each experimental condition) and analyzed the localization of the different compounds in brain sections after $1 \mathrm{~h}$ from injection, by means of the differential labeling of Enf and MYTS with AF660 and FITC, respectively (Figure 4). Immunodecoration of the endothelial cells with anti-CD31 antibody revealed a huge intracellular accumulation for MYTS. As expected, the ability of free Enf to enter BBB endothelial cells and reach brain parenchyma was negligible, while conjugation of the peptide to the nanoparticles allowed it to cross the barrier. Merge between Enf and MYTS signals in samples treated with Enf-MYTS clearly showed that only the peptide was able to diffuse outside the BBB, while nanoparticles were restricted to the vessel endothelium. This result, in agreement with in vitro observations, further suggested the dissociation of the nanocomplex within endothelial cells, with subsequent excretion of Enf.

The systemic toxicity of administered formulations was then assessed by histopathological examination of brain, liver, kidneys, spleen, and lungs isolated $1 \mathrm{~h}$ after Enf, MYTS or
Enf-MYTS injection. Analysis was performed on organs 364 specimens from three different animals for each experimental 365 condition. No histological lesions were observed in the analyzed 366 organs (Figure 5).

Fate of MYTS in RBMVECS

The mechanism of MYTS entry and trafficking into the 369 RBMVECs was investigated by TEM analysis on BBB-bearing 370 inserts after 4, 7 or $24 \mathrm{~h}$ from the addition of Enf-MYTS in the 371 upper chamber. Figure $6, A$ shows that, at $4 \mathrm{~h}$ of incubation, 372 nanoparticles were either attached to the plasma membrane of the 373 endothelial cells or internalized in the cytosol. The lack of 374 membrane invaginations and the presence of free nanoparticles in 375 the cytoplasm suggest that a non-endocytotic mechanism is 376 involved in the internalization of MYTS by RBMVECs, as 377 confirmed also by TEM images of brain samples exposed in vivo to 378 the nanocomplex (Figure S4). Macropinocytosis rafts were also 379 visible where a large number of nanoparticles came in contact with 380 the cellular membrane. Once internalized, MYTS accumulated 381 into large cellular compartments (Figure 6, $A$ and $B$ ), and after 382 $24 \mathrm{~h}$ of incubation, they were also detected into lysosomes 383 (Figure $6, C$ ). The same result was obtained by incubating the cells 384 with the unconjugated MYTS.

385

\section{Discussion}

386

The BBB is the boundary that isolates brain tissues from the 387 substances circulating in the blood and at the same time allows 388 water and small lipophilic molecules to freely access the brain in 389 

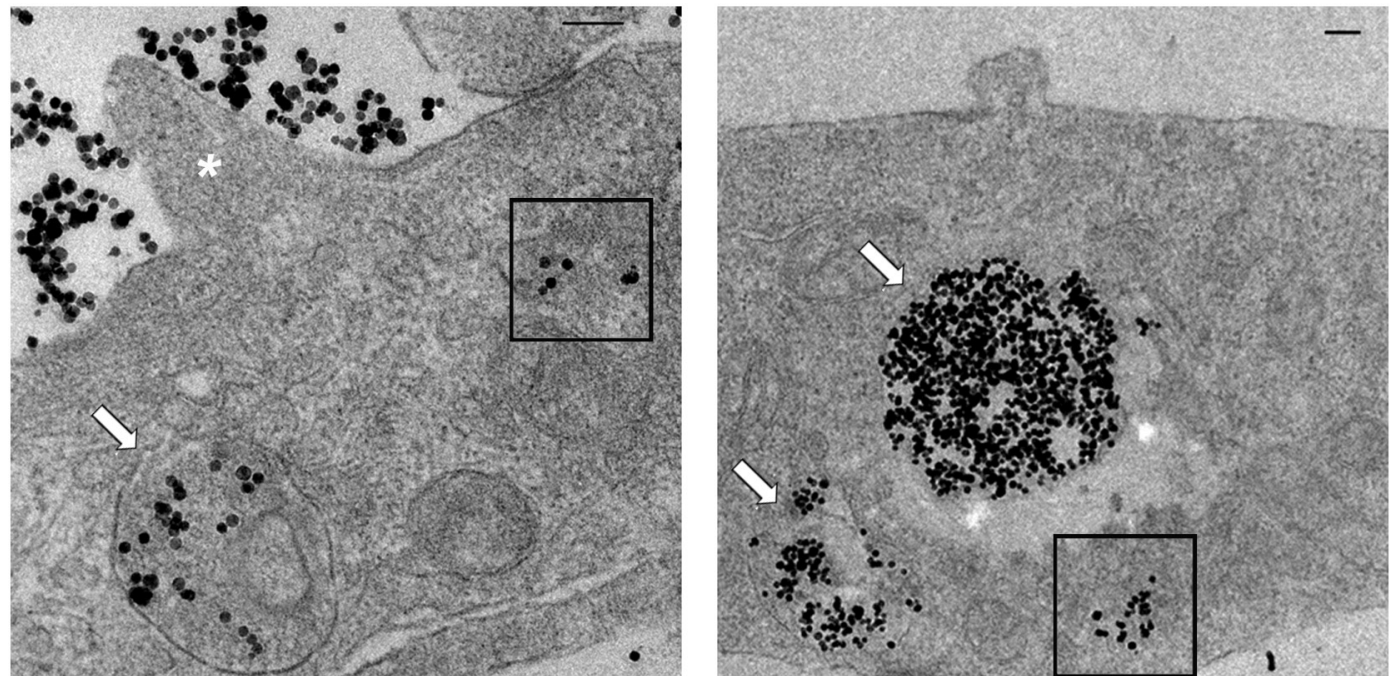

A

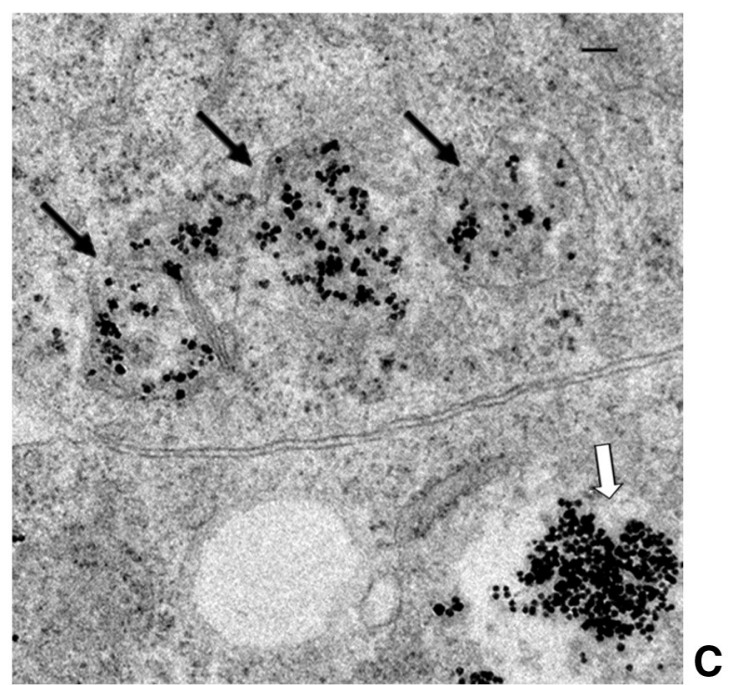

Figure 6. TEM images of RBMVECs in a BBB in vitro model exposed to $0.1 \mathrm{mg}$ Enf-MYTS for $4 \mathrm{~h}(\mathbf{A}), 7 \mathrm{~h}$ (B) and $24 \mathrm{~h}(\mathbf{C})$. MYTS are localized in big cell compartments (white arrows), in lysosomes (back arrows) or free into the cytosol (boxes); asterisk indicates a macropinocytosis raft; bars: $100 \mathrm{~nm}$.

accordance with their concentration gradients. Within this barrier, the brain microvascular endothelial cells, phenotypically different from the endothelial cells of the peripheral circulation, hamper the filtration of therapeutic drugs, preventing them to reach the pathological tissues behind them. To permeate through the BBB, molecules need to be lipid soluble with a molecular weight $<400 \mathrm{Da}$. Heavier and larger molecules, which are unable to diffuse through the BBB because of their size, weight and/or polarity, could cross the BBB only if transported by receptor-mediated transcytosis using ligands that bind specific BBB receptors. Therefore, drugs permeability across the BBB represents a clinical and biological challenge.

It is well established that a double correlation between HIV infection and the brain exists: HIV replication plays a major role in neurological diseases, and CNS is one of the main viral reservoir. During the acute phase of infection HIV-1 rapidly infiltrates the CNS; there the viral replication can occur despite a complete drug-induced suppression of the virus in the peripheral blood. Noteworthy, while about $50 \%$ of HIV-infected patients are affected by neurological disease, evident morphological alterations in CNS are observed in at least $80 \%$ of AIDS patients 410 autopsies. ${ }^{30}$ The acclaimed model for HIV-related injury of CNS 411 involves the release from infected or activated glial cells 412 (microglia and astrocytes) of numerous neurotoxic viral or 413 cellular factors, which lead to neuronal damage and death, and of 414 chemoattractants able to promote infiltration of infected and/or 415 activated monocytes. ${ }^{4}$

In NeuroAIDS prevention, nanotechnology has been intense- 417 ly explored with the aim to develop novel and promising drug 418 delivery systems, and several experimental attempts have been 419 carried out in last years in order to enhance the BBB permeability 420 toward antiretroviral drugs. Indeed, BBB has been demonstrated 421 to be impermeable to $98 \%$ of antiretroviral drugs. ${ }^{31}$ In 2006, Kuo 422 and colleagues have incorporated two antiretroviral drugs, 423 zidovudine and lamivudine, into polymeric polybutylcyanoa- 424 crylate (PBCA) nanoparticles, showing a 8-20 and 10-18 fold 425 increase in BBB permeation, respectively. ${ }^{32}$ However, polymer- 426 ic nanoparticles are not suitable as carriers for polar or ionic 427 drugs, and degradation of PBCA can produce toxic formalde- 428 hyde by-products. ${ }^{31}$ Other biocompatible polymers, such as 429 
polylactide, have been studied as novel nanocarriers for CNS drug delivery, but a transient inflammatory response has been reported. ${ }^{31}$ Conjugation of the protease inhibitor saquinavir with transferrin-conjugated quantum dots has shown improved BBB penetration in vitro, by exploiting an active transport mechanism mediated by transferrin receptors; nevertheless, in vivo results are still missing. ${ }^{14}$ Other nanocarriers such as liposomes are inefficient for loading with water-soluble drugs. ${ }^{31}$

In our study we have designed and developed a novel nanodrug consisting of an iron oxide nanoparticle coated with a suitable amphiphilic polymer and functionalized with the antiretroviral peptide enfuvirtide. Although rarely used in clinical practice, we selected Enf for two main reasons. First, it has proven effective as a non-selective inhibitor of HIV-1 fusion with cells, able to preclude virus entry regardless its co-receptor tropism. The blockade of virus entry into cells is relevant in view of the use of drugs that purge the latent reservoir, damming the circulating HIV-1 pool of virus that should not re-infect new cells. Secondly, Enf is one of the most structurally complex antiretroviral molecules, therefore ideal for testing the efficacy of our nanoconstruct as a drug delivery system to the brain.

So far, the use of iron oxide nanoparticles as antiretroviral carriers has been poorly investigated in vivo. ${ }^{31}$ In the present work, our polymer-coated iron oxide nanoparticles (namely MYTS) have proven to be promising as CNS drug delivery system for antiretroviral drugs, by taking advantage of their intrinsic propensity to cross the $\mathrm{BBB}$. We observed in vitro an increased permeation of nanoformulated Enf across BBB up to $170 \%$ upon $3 \mathrm{~h}$ of incubation. Moreover, conjugated Enf showed increased epifluorescence intensity in mice brain, as a result of its huge CNS accumulation. Electron microscopy images suggested that endocytosis is not likely responsible for the internalization of MYTS in the endothelial cells, even though the presence of a large number of nanoparticles on the cell surface activated the production of macropinocytosis membrane ruffles. Rather, the presence of free nanoparticles in the cell cytoplasm strongly suggests that their internalization mainly occurred by a passive diffusion, probably mediated by the absorption of the amphiphilic coating on the cell membrane. In previous studies, it has been assumed that polymer aggregates carrying hydrophobic groups should have the same affinity for brain endothelial cell membranes of pluronic block copolymers $^{33}$, whose absorption on cell membrane induces a structural alteration of the lipid bilayer. ${ }^{34}$ Membrane fluidization allows the pluronics micelles to enter the microvessel endothelial cells and deliver their cargo into the intracellular environment. ${ }^{34}$ Once into the cell, nanoparticles were sequestered by huge endosome-like compartments and then directed to lysosomes. Our data indicated that Enf dissociated from MYTS in the endothelial cells to be efficiently excreted into the outside environment. The dissociation mechanism requires further studies to be elucidated, but it could involve the degradation of the PMA shells bearing the peptide. PMA degradation feasibly started into the more mature endosomal compartments, as an effect of the increased acidity and enzymatic activity of their inner environment, to be then completed within lysosomes. Concerning Enf efflux, it is known that foreign substances are usually rejected by the BBB through an efflux mechanism based on transporters such as P-glycoprotein and multidrug resistance-associated protein (MRP). ${ }^{35}$ The brain-dir- ected efflux of Enf could occur via MRP4, a protein expressed on 488 the abluminal membrane of the brain capillary endothelial cells, 489 which were proven to mediate the excretion of different drugs, 490 including some antiretrovirals. ${ }^{36}$ Histopathological analysis of 491 brain, spleen, lung, liver and kidneys dissected from mice upon Enf 492 treatment, confirmed that this antiretroviral drug does not exert 493 toxic effects. Moreover, the lack of any organ lesion in the presence 494 of circulating MYTS is a clear evidence of the systemic safety of 495 these nanoparticles at the experimental dosage, further supporting 496 their great potential as drug delivery system across the BBB. $\quad 497$

In conclusion, this is the first documented experience of a 498 nanotechnological engineering of the complex antiretroviral 499 drug enfuvirtide, which conferred to this large peptide the 500 capability to cross the BBB. Whether and how the propensity of 501 Enf nanoconjugate to cross the BBB could affect the viral 502 replication in the CNS sanctuary remain to be established, and 503 further studies will be performed to assess the antiviral efficacy 504 of Enf after trans-BBB permeation. However, at present, our 505 results represent an important step forward toward HAART-me- 506 diated HIV eradication from the CNS reservoir. Since MYTS 507 nanoparticles can be loaded with multiple drugs of different 508 classes, the present study suggests a straightforward approach for 509 targeting various phases of viral replication in the CNS.

\section{Appendix A. Supplementary data}

Supplementary data to this article can be found online at 512 http://dx.doi.org/10.1016/j.nano.2015.03.009.

\section{References}

1. Sarmati L, Parisi SG, Montano M, Andreis S, Scaggiante R, Galgani A, et 515 al. Nevirapine use, prolonged antiretroviral therapy and high CD4 nadir 516 values are strongly correlated with undetectable HIV-DNA and -RNA 517 levels and CD4 cell gain. J Antimicrob Chemother 2012;67:2932-8. 518

2. Cory TJ, Schacker TW, Stevenson M, Fletcher CV. Overcoming 519 pharmacologic sanctuaries. Curr Opin HIV AIDS 2013;8:190-5. 520

3. Bunupuradah T, Bowonwattanuwong C, Jirajariyavej S, Munsakul W, 521 Klinbuayaem V, Sophonphan J, et al. HIV-1 genital shedding in HIV- 522 infected patients randomized to second-line lopinavir/ritonavir mono- 523 therapy versus tenofovir/lamivudine/lopinavir/ritonavir. Antivir Ther 524 2014;24, http://dx.doi.org/10.3851/IMP2737.

4. Kramer-Hämmerle S, Rothenaigner I, Wolff H, Bell JE, Brack-Werner 526 R. Cells of the central nervous system as targets and reservoirs of the 527 human immunodeficiency virus. Virus Res 2005;11:194-213. 528

5. Surdo M, Cortese MF, Perno CF, Aquaro S. NeuroAIDS: virological 529 aspects of HIV infection. $J$ Biol Regul Homeost Agents 2013;27:115-28. 530

6. Doyon G, Sobolewski MD, Huber K, McMahon D, Mellors JW, Cremer 531 NS. Discovery of a small molecule agonist of phosphatidylinositol 532 3-kinase $\mathrm{p} 110 \alpha$ that reactivates latent HIV-1. PLoS One 2014;29, http:// 533 dx.doi.org/10.1371/journal.pone.0084964.

7. Wightman F, Lu HK, Solomon AE, Saleh S, Harman AN, Cunningham 535 $\mathrm{AL}$, et al. Entinostat is a histone deacetylase inhibitor selective for class 1536 histone deacetylases and activates HIV production from latently infected 537 primary T cells. AIDS 2013;27:2853-62.

8. Shan L, Xing S, Yang HC, Zhang H, Margolick JB, Siliciano RF. 539 Unique characteristics of histone deacetylase inhibitors in reactivation of 540 latent HIV-1 in Bcl-2-transduced primary resting CD4 $+\mathrm{T}$ cells. 541 $J$ Antimicrob Chemother 2014;69:28-33. 
9. Kent SJ, Reece JC, Petravic J, Martyushev A, Kramski M, De Rose R, et al. The search for an HIV cure: tackling latent infection. Lancet Infect Dis 2013;13:614-21.

10. Parboosing R, Maguire GEM, Govender P, Kruger HG. Nanotechnology and the treatment of HIV infection. Viruses 2012;4:488-520.

11. Mamo T, Moseman EA, Kolishetti N, Salvador-Morales C, Shi J, Kuritzkes DR, et al. Emerging nanotechnology approaches for HIV/ AIDS treatment and prevention. Nanomedicine (Lond) 2010;5:269-85.

12. Amiji MM, Vyas TK, Shah LK. Role of nanotechnology in HIV/AIDS treatment: potential to overcome the viral reservoir challenge. Discov Med 2006;6:157-62.

13. Mahajan SD, Aalinkeel R, Law WC, Reynolds JL, Nair BB, Sykes DE, et al. Anti HIV-1 nanotherapeutics: promises and challenges for the future. Int J Nanomedicine 2012;7:5301-14.

14. Mahajan SD, Roy I, Xu G, Yong KT, Ding H, Aalinkeel R, et al. Enhancing the delivery of anti retroviral drug "saquinavir" across the blood brain barrier using nanoparticles. Curr HIV Res 2010;8:396-404.

15. Trottier B, Walmsley S, Reynes J, Piliero P, O’Hearn M, Nelson M, et al. Safety of enfuvirtide in combination with an optimized background of antiretrovirals in treatment-experienced HIV-1-infected adults over 48 weeks. J Acquir Immune Defic Syndr 2005;40:413-21.

16. Liu S, Lu H, Niu J, Xu Y, Wu S, Jiang S. Different from the HIV fusion inhibitor C34, the anti-HIV drug Fuzeon (T-20) inhibits HIV-1 entry by targeting multiple sites in gp41 and gp120.J Biol Chem 2005;280:11259-73.

17. Patel IH, Zhang X, Nieforth K, Salgo M, Buss N. Pharmacokinetics, pharmacodynamics and drug interaction potential of enfuvirtide. Clin Pharmacokinet 2005;44:175-86.

18. Dando TM, Perry CM. Enfuvirtide. Drugs 2003;63:2755-66.

19. Borrego P, Calado R, Marcelino JM, Bártolo I, Rocha C, Cavaco-Silva $\mathrm{P}$, et al. Baseline susceptibility of primary HIV-2 to entry inhibitors. Antivir Ther 2012;17:565-70.

20. Sista P, Melby T, Greenberg ML, Davison D, Jin J, Mosier S, et al. Characterization of baseline and treatment-emergent resistance to T-20 (enfuvirtide) observed in phase II clinical trials: substitutions in gp41 amino acids 36-45 and enfuvirtide susceptibility of virus isolates. Antivir Ther 2002;7:S16-7.

21. Cilliers T, Patience T, Pillay C, Papathanasopoulos M, Morris L. Sensitivity of HIV type 1 subtype $\mathrm{C}$ isolates to the entry inhibitor T-20. AIDS Res Hum Retroviruses 2004;20:477-82.

22. Derdeyn CA, Decker JM, Sfakianos JN, Zhang Z, O'Brien WA, Ratner $\mathrm{L}$, et al. Sensitivity of human immunodeficiency virus type 1 to fusion inhibitors targeted to the gp41 first heptad repeat involves distinct regions of gp 41 and is consistently modulated by gp 120 interactions with the coreceptor. J Virol 2001;75:8605-14.
23. Price RW, Parham R, Kroll JL, Baker B, Sailstad J, Hoh R, et al. 587 Enfuvirtide cerebrospinal fluid (CSF) pharmacokinetics and potential 588 use in defining CSF HIV-1 origin. Antivir Ther 2008;13:369-74. 589

24. Park J, An K, Hwang Y, Park JG, Noh HJ, Kim JY, et al. Ultra-large- 590 scale syntheses of monodisperse nanocrystals. Nat Mater 2004;3:891-5. 591

25. Pellegrino T, Manna L, Kudera S, Liedl T, Koktysh D, Rogach AL, et al. 592 Hydrophobic nanocrystals coated with an amphiphilic polymer shell: a 593 general route to water soluble nanocrystals. Nano Lett 2004;4:703-7. 594

26. Bazylinska U, Kulbacka J, Wilk WA. Dicephalic ionic surfactants in 595 fabrication of biocompatible nanoemulsions: factors influencing droplet 596 size and stability. Colloids Surf A Physicochem Eng Asp 597 2014; $460: 312-20$.

27. Alkilany AM, Abulateefeh SR, Mills KK, Bani Yaseen AI, Hamaly MA, 599 Alkhatib HS, et al. Colloidal stability of citrate and mercaptoacetic acid 600 capped gold nanoparticles upon lyophilization: effect of capping ligand 601 attachment and type of cryoprotectants. Langmuir 2014;30:13799-808. 602

28. Zaharoff DA, Hance KW, Rogers CJ, Schlom J, Greiner J. Intratumoral 603 immunotherapy of established solid tumors with chitosan/IL-12. J 604 Immunother 2010;33:697-705.

29. Fiandra L, Mazzucchelli S, De Palma C, Colombo M, Allevi R, 606 Sommaruga S, et al. Assessing the in vivo targeting efficiency of 607 multifunctional nanoconstructs bearing antibody-derived ligands. ACS 608 Nano 2013;7:6092-102.

30. De Almeida SM, Letendre S, Ellis R. Human immunodeficiency virus 610 and the central nervous system. Braz J Infect Dis 2006;10:41-50. 611

31. Sagar V, Pilakka-Kanthikeell S, Pottathil R, Saxena SK, Nair M. 612 Towards nanomedicines for neuroAIDS. Rev Med Virol 613 2014:24:103-24.

32. Kuo YC, Chen HH. Effect of nanoparticulate polybutylcyanoacrylate 615 and methylmethacrylate-sulfopropylmethacrylate on the permeability of 616 zidovudine and lamivudine across the in vitro blood-brain barrier. Int $J 617$ Pharm 2006;327:160-9.

33. Hemmelman M, Knoth C, Schmitt U, Allmeroth M, Moderegger D, Barz 619 M, et al. HPMA based amphiphilic copolymers mediate central nervous 620 effects of domperidone. Macromol Rapid Commun 2011;32:712-7. 621

34. Batrakova EV, Li S, Vinogradov SV, Alakhov VY, Miller DW, 622 Kabanov AV. Mechanism of pluronic effect on P-glycoprotein efflux 623 system in blood-brain barrier: contributions of energy depletion and 624 membrane fluidization. J Pharmacol Exp Ther 2001;299:483-93. 625

35. Demeule M, Regina A, Jodoin J, Laplante A, Dagenais C, Berthelet F, et al. 626 Drug transport to the brain: key roles for the efflux pump P-glycoprotein in 627 the blood-brain barrier. Vascul Pharmacol 2002;38:339-48.

36. Löscher W, Potschka H. Drug resistance in brain disease and the role of 629 drug efflux transporters. Nat Rev Neurosci 2005;6:591-602. 


\section{ARTICLE IN PRESS}

Nanomedicine: Nanotechnology, Biology, and Medicine $\mathrm{xx}(2015) \mathrm{xxx}-\mathrm{xxx}$ nanomedicine

Nanotechnology, Biology, and Medicine

Graphical Abstract

Nanoformulation of antiretroviral drugs enhances their penetration across the blood brain barrier in mice

Luisa Fiandra, $\mathrm{PhD}^{\mathrm{b}}$, Miriam Colombo, $\mathrm{PhD}^{\mathrm{c}}$, Serena Mazzucchelli, $\mathrm{PhD}^{\mathrm{b}}$, Marta Truffi, PhD ${ }^{\mathrm{a}}$, Benedetta Santini, BPharm ${ }^{\mathrm{c}}$, Raffaele Allevi, CLT ${ }^{\mathrm{a}}$,

Manuela Nebuloni, $\mathrm{PhD}^{\mathrm{a}}$, Amedeo Capetti, $\mathrm{MD}^{\mathrm{b}}$, Giuliano Rizzardini, $\mathrm{MD}^{\mathrm{b}}$, Davide Prosperi, $\mathrm{PhD}^{\mathrm{c}, \mathrm{d}}$, Fabio Corsi, $\mathrm{MD}^{\mathrm{a}}{ }^{\mathrm{a}}$,

aDipartimento di Scienze Biomediche e Cliniche "Luigi Sacco", Università di Milano, Milano, Italy ${ }^{\mathrm{b}}$ Ospedale L. Sacco, Milano, Italy

${ }^{\mathrm{c}}$ Dipartimento di Biotecnologie e Bioscienze, Università di Milano-Bicocca, Milano, Italy

${ }^{\mathrm{d}}$ Laboratorio di Biofisica e Nanomedicina, Polo Tecnologico, Fondazione Don Gnocchi IRCCSONLUS, Milan, Italy

Enfuvirtide-conjugated MYTS, intravenously injected in mice, reach the brain microvascular endothelium and are internalized by the endothelial cells to release the drug in brain parenchyma.
Nanomedicine: Nanotechnology, Biology, and Medicine $x x x$ (2015) xxx-xxx

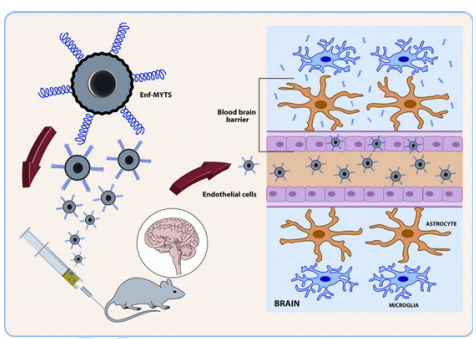

